\title{
Adulthood: the Contemporary Redefinition of a Social Category
}

\author{
by Harry Blatterer \\ Macquarie University \\ Sociological Research Online, Volume 12, Issue 4, \\ < http://www.socresonline.org.uk/12/4/3.htm/> \\ doi:10.5153/sro. 1563
}

Received: 10 Jan 2007 Accepted: 3 Jul 2007 Published: 31 Jul 2007

\begin{abstract}
Social trends such as delayed or forfeited family formation, postponed home leaving and allegedly infantilising leisure practices are often marshalled in support of a long standing social scientific as well as popular assumption: successive generations take longer to reach adulthood. This article argues that this 'delayed adulthood thesis' is based on an anachronistic model of adulthood and goes on to suggest an alternative conception. Some original interview material with individuals in their late twenties as well as the notion of social recognition are utilized in this process. It is suggested that the very practices that serve as evidence for the delayed adulthood thesis are in fact productive of new, emerging modalities of adulthood that are commensurate with changed and changing social realities.
\end{abstract}

\section{Keywords: Adulthood; Adolescence; Emerging Adulthood; Early Adulthood; Biography; Life Course; Recognition; Social Change}

\section{Introduction}

1.1 Working nine to five, dinner parties, jury duty and voting; marriages, mortgages and children; the family sedan, adultery and divorce; investment portfolios, nest eggs, life insurance, writing a will - these are things we do, strive for or object to, hold dear, or consider commonplace. None of these words are associated with childhood or adolescence; all of them connote in one way or another the responsibilities, commitments and autonomy of adulthood. And just as these words describe ordinary possessions, practices and relationships, so adulthood too has something less than remarkable about it. In fact, for most people today who consider themselves grown up adulthood is no mystery; it is the middle period of our lives that follows adolescence.

1.2 As lay participants in everyday life we evaluate other's as well as our own attainment or nonattainment of adult status according to objective achievements such as stable fulltime work, stable relationships, independent living and parenthood. That is, although we experience them as personal circumstances we usually do not personally create these benchmarks in order specifically to mark our adulthood. These benchmarks are deeply ingrained in the culture as part of a preexisting assembly of representations and achievements that denote adult status. This is also where the seeming banality of the word 'adulthood' ends. For embedded in the word are cultural semantics that - often subtly, sometimes explicitly - provide us with clues about what it means to be welcomed into society as full members. This process of acknowledgement is one of mutuality. It is neither a matter of crossing a threshold or passing a rite of passage once and for all, nor a one-way trajectory of gradual adaptation. Rather, it is, as I will suggest in this article, a dynamic, intersubjective process of social recognition in which collectivities and individuals are inescapably implicated. Our validation as full adults occurs in our dealings with the most removed and abstract state institutions; it shapes our experiences and subjectivities at school and at work, and it is vital to our friendships and intimate relations as well as our everyday encounters with strangers. Although I cannot address all of these issues in a article such as this, what I hope to do is to explore the social constitution of adulthood particularly as it pertains to affluent societies and milieux and so to provoke discussion rather than provide conclusive evidence. I begin by outlining the status of adulthood as a category in social scientific and public discourse. Second, I will address some social changes that precipitate a further problematization of this social category and illustrate those with selected themes from a qualitative study (Blatterer 2007). Finally I will elaborate a reconceptualization that takes heed of the social transformations which frame the emergent qualities of adulthood. ${ }^{[1]}$ 


\section{Adulthood as central and marginal}

2.1 The notion of the adult, the life stage this figure is supposed to inhabit and the status with which it is associated, tacitly informs the majority of sociological analyses whenever an actor needs to enter the scene. Indeed, 'the adult' represents the actor par excellence as if, in Norbert Elias's words, she 'was never a child and seemingly came into the world as an adult (1978: 248). Only when childhood and old age are specifically at issue does this secondary support cast take centre stage. But here too, in our concerns with the elderly and the very young, adulthood represents the central category against which social and biological development is measured. In the social scientific imagination as well as in common sense, the child, not yet a full human being, is conjured as a 'human becoming' (Qvortrup 1994); the elderly, on the other hand, are no longer what, in times of full capacity, they once were. The classic image of the life cycle, where senility returns the child to the helpless dependence which marked her beginning, is the key social representation of this perspective.

2.2 Its very centrality renders adulthood in scarce need of explication, not least because it is the embodied reality of sociologists who, from their adult vantage point, have their own memories of childhood, their own fears of ageing, and thus bring a natural attitude to their experiences as well as to their calling that makes their adulthood as well as that of others self-evident. The centrality of this category is most clearly evident in those sociological investigations that attend to what is known as 'youth transitions.' This is not only a vast area in the sociology of youth, but it is one that is immensely important because policy recommendations concerning the transition from education to work take their cues from practitioners in this research domain. But here the marginality of adulthood also comes to the fore. Indeed, the notion of a transition from youth to adulthood is the principal case which highlights the contradiction inherent in our conception of what it means to be grown up. Firstly, for practical reasons researchers rarely question the empirical validity of boundaries between life stages. Secondly, and more importantly for the present discussion, only a notable few stop to think what the perceived destination at transition's end actually represents, what its meaning in contemporary society may be (e.g. Pilcher 1995; Dwyer \& Wyn 2001; Pilcher et al. 2003; Wyn 2004; Holdsworth \& Morgan 2005; Crawford 2006; Blatterer 2007). By and large, adulthood remains conceptually fixed, taken for granted and under-theorized.

\section{Public opinion and expert discourse}

3.1 In parallel to the under-theorized nature of adulthood in sociology, there is much public discourse that either bemoans children's precociousness, or young people's reluctance to grow up. While some commentators tell us that children grow up too quickly these days, others speak about the obverse and hold that young people either refuse to grow up or reject adulthood altogether. These conclusions are based on the observation of social trends that are seen, and sometimes shown, to be evident among individuals in their 20s and 30s: delayed or forfeited family formation and marriage, which some find particularly alarming as the birth rate keeps dropping beneath the replacement rate in our ageing societies; prolonged stay in or frequent returns to the parental home; long periods of education; people's alleged preferences for living in the present for its own sake, and leisure practices that are perceived as signs of infantilization, such as playing computer games and reading Harry Potter (Furedi 2003). The drivers of these attitudes and practices are regularly assumed to be a rampant consumerism in conditions of 'affluenza' (Hamilton \& Denniss 2005), a proliferation of options in all spheres of life and the usual suspect: a prevalent, everworsening atomizing individualism that precipitates a steady and ineluctable moral decline. All in all, there appears to be a general sentiment to the effect that young people defer or altogether eschew adulthood. Although I recognize that hyperbole is a stock in trade of the popular press, some selected Australian headlines are nevertheless instructive: 'Now Wait til 35 for Coming of Age' (The Australian 2001), "Adults' Fail the Age Test' (Herald Sun 2004), 'Kids Who Refuse to Grow Up' (Herald Sun 2003) and 'Forever Young Adultescents Won't Grow Up (MXAustralia 2004).

3.2 In keeping with their arguments, and to enable them to target new consumer demographics, marketing professionals in Australia and elsewhere offer a number of labels describing individuals who are said to be averse to growing up. These labels are readily taken up in the media where there is talk about the rise of 'adultescents,' 'kidults,' and 'twixters' in the U.S. and Australia, 'boomerang kids' in Canada, Nesthocker in German speaking countries, mammone in Italy and KIPPERS (Kids In Parents' Pockets Eroding Retirement Savings) in the U.K. (Time 2005). But public discourse and expert knowledge are mutually constitutive. Indeed, attention to young people's deferral or rejection of adulthood can draw on expert advice with a long history. Indebted to Stanley Halls' work (1904), mid-twentieth century North American notions of adolescence as a period of structured irresponsibility (Parsons 1954) and as 'identity crisis' (Erikson 1950) can be considered paradigmatic of western culture's perceptions and treatment of adolescents up to the present. Taking the 'storm and stress' view of adolescence as a given, psychoanalyst Peter Blos (1941) coined the term post-adolescence in the 1940s. It designates a stage of life inhabited by individuals who have outgrown adolescence but have not yet reached adulthood. These are individuals who, according to 
Keniston (1970: 634) 'far from seeking the adult prerogative of their parents ... vehemently demand a virtually indefinite prolongation of their non-adult state.' Erikson's (1968) 'prolonged adolescence' neatly encapsulates this idea.

3.3 While some still insist that adolescence continues to be prolonged, others slot in new life stages between adolescence and full adulthood. I will briefly respond to one such approach below. For analytic clarity I subsume this tendency in the media and the social sciences under the heading delayed adulthood thesis. Simply put, this thesis equates the social trends I listed above with an extended transition to and delayed entry into full adulthood. Furstenberg (2000: 898) sums up the prevailing accord: 'the transition to [full] adulthood extend[s] well into the third decade of life and is not completed by a substantial fraction of young people until their 30s.' The issue becomes rather confusing though when members of the U.S. Society for Adolescent Medicine state: 'Adolescents who are age 18 or older are adults' (Ford et al. 2004: 164). There is simply no social scientific consensus on endings and beginnings. There is only agreement that today young people take longer to reach full adulthood than was previously the case.

\section{An emerging social science orthodoxy}

3.4 To accommodate the demographic changes that lie at the root of the allegedly extended and delayed entry into adulthood, two conceptions of North American provenance have gained particular currency: Jeffrey Arnett's emerging adulthood (e.g. Arnett 2000a, 2000b, 2004) and Frank Furstenberg's early adulthood (2003). Both perspectives are based on the belief that a new life stage separates adolescence from adulthood. Emerging adulthood pertains to individuals between 18 and approximately 25 years of age who, '[h]aving left the dependency of childhood and adolescence, and having not yet entered the enduring responsibilities that are normative in adulthood' inhabit an in-between stage (Arnett 2000a: 469). Early adulthood describes a phase from the late teens to the late 20 s or early 30 s when 'young people have not yet become fully adult because they are not ready or able to perform the full range of adult roles' (Furstenberg 2003: 1). The difference between these approaches is one of nomenclature. This does not detract from the reality that Arnett's and Furstenberg et al's research makes important contributions to the study of young people's life trajectories. Nevertheless, there are some problems inherent in these contiguous conceptions. To this end the following statement may be considered programmatic not only for Arnett's approach, but for much of the oeuvre:

The more individualistic a culture becomes, the more the transition to adulthood is individually rather than socially defined. It takes place subjectively, individually, internally, in an individual's sense of having reached a state of self-sufficiency, emotional self-reliance and behavioral selfcontrol. (Arnett \& Taber 1994: 533)

This assertion fits hand in glove with the claim made by Côté. 'Adulthood,' he asserts, 'is now more a psychological state than a social status' (2000: 31).

3.5 I argue that this approach takes a particular model of full adulthood as the benchmark against which contemporary social trends are evaluated and young people's practices are judged. Borrowing the term from Nick Lee (2001) upon whose considerations much of this section relies, I refer to this model as 'standard adulthood,' and maintain that it is based on a historically and culturally specific understanding of what it means to be grown up. More precisely, I suggest that no other time in the history of western societies has been more conducive to the cementing of our conception of adulthood than the period between the end of the Second World War and the oil crises of the early 1970s, Eric Hobsbawm's 'Golden Age' (Hobsbawm 1996: 223-402). The social and economic conditions of the period have been extensively discussed and analysed and their parameters are well known. What is of importance in this discussion is the relatively high degree of standardization of the life course that was produced by these conditions (e.g. Kohli 1986) -a standardization which, moreover, went hand-in-hand with an overreaching and universally accepted value-system, at least until the 1960s when previously proscribed behaviours were becoming less problematic (Thornton \& Young-De Marco 2001). Within this value-system the heterosexual nuclear family prevailed as the ideal adult living arrangement which to a significant degree was made possible by the security and stability provided by the labour market of the time (Lee 2001: 7-20). It follows that becoming an adult-then-was a matter of following a life course that included what I call the classic markers of adulthood: family, work and independent living. These became objective markers of adulthood and were relatively fixed in time. Thus, when long-term fulltime work was within reach for the majority and early marriage and parenthood so common, the meaning of being 'grown up' was perfectly clear, and the attainment of the classic markers brought with them the recognition of adult status. Notwithstanding real individual differences in life experiences, this vision of adulthood held secure normative status as the guiding model, and to a large extent it still does. Our contemporary association of adulthood with stability has retained much of the cultural value passed down from generation to generation, and that despite often radical social changes that have occurred in the meantime. 


\section{Adulthood and social change: some articulations}

3.6 Although standard adulthood remains robust as a norm, the very conditions for its attainment are disappearing, or have indeed disappeared. Again, the circumstances of the recent past and the present are well documented and understood. To pick two examples, we may think here about the insecurities of the part-time labour market and the diminishment of collectively negotiated guarantees in the sphere of work, but also about the transformation in intimate relationships, which today tend to be negotiated around fairly intangible psychological needs (Giddens 1992; Jamieson 1998). In fact, there is a strong consensus in sociology that in affluent milieux the life course is much more fragmented today, that its tendency towards linearity, which was once underpinned by a normative pattern of age-appropriate life events, is no longer a reality for many individuals born roughly after 1970, and that this has a significant impact on how individuals negotiate their biographical trajectories (e.g. Dwyer \& Wyn 2001; Hockey \& James 2003; Settersten 2003; Holdsworth \& Morgan 2005). The turn in social theory towards risk, uncertainty and reflexivity in the 1990s can be seen as an attempt conceptually to grasp these changes (e.g. Giddens 1990, 1991; Beck 1992; Beck et al. 1994). While we could go on to debate the many downfalls as well as merits of these developments, one thing is indisputable: the temporal securities of the postwar era, which allowed people to plan a relatively coherent life trajectory well into the future, do no longer exist. ${ }^{[2]}$

3.7 At this point it is worthwhile to listen to what some people between 25 and 35 years of age have to say about the uncertainties that arise with new social exigencies; how they cope with these; and how they impact upon the meaning of adulthood.

\section{A note on method}

3.8 What follows is material selected from a more elaborated body of in-depth, semi-structured interviews (Blatterer 2007). Inclusion of this material in this article is intended solely to establish an orientating link between experiences and the reconceptualization of adulthood which follows. Commensurate with 'the logic of small samples in qualitative research', the results do - emphatically - not aim at the kind of scope that representative, enumerative studies may provide, but rather at depth (Crouch and McKenzie 2006). That is to say, I seek to identify perceptions, experiences and attitudes in order to gain insights into contemporary adulthood as lived experience. The respondents' stories - however abridged here - are invaluable guideposts toward a better understanding of a research area particularly when, as in the present case, that area is relatively under-explored. Thus, the following excerpts are best read as theory-guiding and exploratory.

\section{The respondents}

3.9 To ensure anonymity I have assigned pseudonyms to the respondents.

Christopher (25) was raised in the Blue Mountains to the west of Sydney and holds an Honours degree in sociology. He works for a national employment service.

David (29) grew up in a working-class suburb of Sydney and is the first child of an ethnically mixed couple to undertake tertiary studies. He lives with his parents.

Ethan (28) is a musician who has recently decided to go back to university in order to further his education. Ethan grew up in suburban Sydney, the only son of a working-class family.

Greg (26) comes from a small country town in New South Wales. He moved to Sydney some three years ago and works for a large retailer as a shop assistant.

\section{Shortened time horizons and the normalization of uncertainty}

4.1 For some interviewees the possibilities for long-term life planning in the past, and their relative lack in the present are fundamental in their comparisons between their parents' growing up and their own. Christopher makes the point strongly:

I think it's a huge, huge difference that my parents and most people of that generation could assume they were gonna get a job, and could assume that they could get a fulltime job. And so there follows a whole lot of presumptions from that: 'I'l probably be able to buy a house, I'll probably be able to buy a car,' these material things. But also, it's not as much of a preoccupation in a sense.

4.2 To emphasize what he perceives as the then unquestioned normality of this situation Christopher adds 
that this was so for his parents even though they were following an usual path: 'And I find it strange because my parents were unorthodox in the sense that they actively and consciously tried to break that mould'.

4.3 This respondent's perplexity can be demystified: precisely because standard adulthood represented a realizable frame of reference, it provided a bedrock of security that existed in principle for everyone, even for those who did not fit into that frame; even for those who did not envisage themselves as having to rely on those securities. Those who broke the mould still knew what mould they were breaking, what they were gaining or losing, embracing or rejecting, in what social context. Today, Christopher remarks,

you can't expect ... the flow of things, like it's going to be normal. And I do expect, you know, I'll probably have four different careers. That would have never crossed my parents' generation's mind. I think uncertainty has become a taken-for-granted part of my life, in a way that it wasn't for them, and I think ... it's a normal state of affairs [for us] whereas I just don't think my parents'generation would conceptualize it in the same way.

4.4 As a consequence of this normalization of uncertainty it is not necessarily perceived in negative terms. To the contrary, behind a thinly veiled objective precariousness lies the ever-present perceived potential for more freedom: 'I think this is where I see a transformative potential and hope. When contingency and uncertainty are normals of existence, your receptivity to change is higher, because change becomes a more normal aspect of life' (Christopher).

4.5 But also underlying this perception of adaptability is individuals' trust in their capacity to counter any untoward consequences of uncertainty by making the right choices at the right time. Greg's is a summary statement: 'There are that many more opportunities at your fingertips these days ... Our lives are much more diverse, there is more choice'. This perception of a proliferation of options in all areas of life is central to the redefinition of contemporary adulthood. And it is so important because a perception of unlimitedness, particularly when this perception is framed by conditions of uncertainty, calls for the future to be open because a foreclosed future limits options. Longitudinal research has shown that this is a common perception among young people (Wyn \& White 2000; Dwyer \& Wyn 2001). This is not necessarily a new situation per se. In his writing on time Dilthey had the following to say: 'In our attitude to the future we are active and free. Here the category of reality which emerges from the present is joined by that of possibility. We feel that we have infinite possibilities' (1986: 150). However, the connection between present realities and future possibilities is qualitatively different when the life course is less ambiguously normatively circumscribed. Thus uncertainties that arise from the devolvement of the institutionalized life course, from the individualization of biographies - and I mean here uncertainty as a taken for granted aspect of life - paradoxically create a need for an unpredictable future. 'Wish fulfilment is the death of future', states Christopher glibly.

4.6 And this is precisely where the cultural vision of standard adulthood, and the notions of stability with which it is associated, no longer functions as a realistic, practicable precept even though it remains as a norm.

\section{A new fatalism}

5.1 The interviewees had a keen sense of what is meant by adulthood. And almost exclusively they describe it in the terms offered by one respondent who says, 'adulthood seems like the full-stop I'm reluctant to apply' (Ethan). The standard model, though a measure of judgement, simply doesn't offer the flexibility required in the contemporary era. This is interesting in so far as we know that a feeling of control over one's life trajectory is pivotal to individuals' sense of well-being (Mirowsky \& Ross 2003). But it appears to be the case that a kind of surrendering to uncertainty underpinned by a strong faith that, in principle, they can rely on their own resources to get them through, provides the respondents with that sense of control over the future. These are signs of a new fatalism that are evident in statements such as 'whatever happens will happen' (David). In that fatalism resides a good measure of hope. My respondents would likely agree with Theodore Zeldin's (1994: 373) statement that '[t]he shape of hope is always uncertain, and uncertainty is indispensable to hope.'

5.2 This mentality differs in at least one important aspect from the fatalism conventionally associated with premodernity (Giddens 1991: 109-43). Rather than giving the future over to external metaphysical forces, it is the self that becomes the idol; it is a fatalism based on trust in individuals' own competencies to deal with whatever life brings. And rather then being testimony to a kind of generational irrationalism, or selfcentredness, it is, perhaps no more than a 'rational response to systemic uncertainty' (Bauman 2001: 52). Rational in this sense implies that rather than uncertainty being countered with a plan-at-all-costs attitude the future is not only recognized as indeterminate, but also actively constructed as such in order to make it bearable. It could be argued that the often commented upon, and empirically verified optimism of many 
members of the younger generation concerning the future (Wyn \& White 2000) can also be interpreted as a coping strategy in the face of otherwise hard to fathom and perhaps even unbearable difficulties concerning their self-projection into the future.

\section{From unnecessary possibility to impossible necessity}

6.1 In the postwar period, long-term planning was not an imperative because this was a real possibility. By contrast, the unpredictability of the present requires continuous reflection concerning one's biography (Giddens 1990, 1991; Beck 1992; Beck et al. 1994). This is a historical shift from the unnecessary possibility to the impossible necessity of life planning - a singular situation, particularly when we consider western history from the mid-twentieth century. For the unpredictability of contemporary life means only short term goals are apt to remain within grasp. Hence, the reputed presentism-living in the present for its own sake-which has become a rarely reflected-upon trope supposed to describe young people's attitudes to life is inaccurate. It seems to me that they live in the present for the sake of the future. And they can do so because the present is, and always was, our immediate terrain of action; it lives, in Dilthey's words, 'in the fullness of our reality' (1986: 150). More accurately, then, what is lost is not the future, nor is it time, but a coherent, collective orientation towards the future. This also has consequences for the way the transition to adulthood is conceptualized.

\section{The social embeddedness of individual transitions}

7.1 As a result of the changes of the recent past markers of transition are individually identified as such rather than socially prescribed. These transitions could be a variety of heterogeneous events or moments: getting your driver's license, any number of firsts, helping a family member conquer trauma, and so forth. Transitions such as these are no longer comparable with collectively understood rites of passage-rituals at the end of which lies adulthood. Rather, they are individual experiences that are often retrospectively assigned symbolic transitionary meaning by the individuals themselves in an ad hoc fashion. As such these transitions do not constitute social markers of adulthood in the strict sense, and indeed, this circumstance is sometimes cited in support of the notion that the transition to and the quality of adulthood is a matter of subjective perception (Arnett \& Taber 1997; Arnett 2004). I suggest that however characteristic this individual sense-making may be of contemporary individualizing tendencies it does not indicate a separation from collective identifications and evaluative distinctions. We know at least since Maurice Halbwachs (1992) that individual memories themselves are socially derived. By definition this means that even those markers of transition that are individually chosen to signify transitions-however ad hoc, and however much they appear to signify atomized individuals-are obtained from pre-existing typifications. To illustrate: though possible, it is highly unlikely that someone would pick their first game of badminton, going to the movies, or plucking their eyebrows as markers of transition to adulthood. It is substantially more likely that someone would choose to assign their first independent purchase, travelling overseas without parents, getting married or giving birth some transitionary significance. This is so because-however hidden, tacit or implied; however unconsidered or even denied-there is a collectively constituted, shared and more or less decipherable repertoire of meaning in which we realize our individual continuity over time. The thesis that markers of transition are becoming individualized therefore needs qualification: no matter to what extent events and experiences are subject to individual sense-making, the range of choices is still culturally delimited, the patterns open to imitation. Thus the individualization thesis makes sense in so far as individuals are free to attribute meaning to their own subjectively singled out transitionary events. However, the notion that adulthood as such is today predominantly a state of mind is thus valid only to that very restricted degree. There are good reasons then to sociologically reconceptualize adulthood in ways that are more adequate to contemporary exigencies. I now turn to one such possible way.

\section{A reconsideration: adulthood and social recognition}

8.1 Some decades before recognition became a discreet research area Goffman (1986: 2) noted: 'When a stranger comes into our presence ... first appearances are likely to enable us to anticipate his category and his attributes, his 'social identity' ... We lean on these anticipations that we have, transforming them into normative expectations, into righteously presented demands.' These are the more intimate moments of social interaction. They may be seen as replicating on the micro level those institutionalized and legislated forms of recognition that, for modern individuals, have become the social foundation upon which their selfunderstanding, and ultimately the self-understanding of their society, rests. Thus knowing who we are is also inseparable from knowing who we can be, and from having as part of our natural attitude an understanding of the normative possibilities for our flourishing as human beings. This basic precept forms the foundation for the concept of social recognition in sociology and social philosophy, particularly as formulated by Honneth (1996) from whom I take my cues.

8.2 At first glance, present uncertainties about the contemporary biography-and by extension adulthood - would seem to fit concerns of those theorists who, according to Honneth (1995: 225), tend to maintain 
that subjects' 'possibilities for freedom are best realized when, independent of all normative expectations and bonds, they are able to creatively produce self-images'. Indeed, contemporary individuals, released from the normative constraints of old, appear to have immense freedoms for experimentation with images of the self. After all, notions such as delayed adulthood not only conjure up a reputed deferral of independence, stability, and responsibility, but also the open-endedness and contingencies of a continuing youthful fascination with various lifestyles and aesthetic self-representations. Honneth is critical of such a view. He reinterprets Hegel's notion of social recognition, pits it against his own reading of postmodern theory and bases his conception on the conviction that,

the freedom of self-realization is not measured according to the distance the individual can establish between himself and the cultural lifeworld, but according to the degree of recognition he can find in his social environment for his freely chosen goals: instead of being defined by the scale of distance from all normative bonds, the increase in personal individuality is determined here by the degree to which individual differences are communicatively granted, indeed encouraged' (1995: 227).

8.3 In this view, recognition is a fundamental human necessity; its presence or absence (in the form of disrespect or 'misrecognition') informs our self-understanding as humans. Because intersubjective recognition is a fundamental human need, it is always in a state of contestation. In true Hegelian spirit, this 'struggle of recognition,' manifested in a ceaseless challenging of norms, values and ways of life, the tension between validity claims and legitimate authority, is the driving force of social change.

8.4 It stands to reason that such a conception lends itself well to theorizing self-conscious, collective struggles, breaches of human rights and the philosophical foundations of social justice. But struggles of recognition also take place in everyday life, where it can simply be our longing for acceptance, for being validated, considered cool or smart or beautiful or powerful, etc. So, if we take both Hegel and Honneth back to everyday concerns, perhaps introduce Goffman into the equation, and consider the way we present ourselves in various social milieux, we can see that in often subtle and unconscious ways we strive for inner congruence with extant dynamics of social recognition. Only then do we feel a good measure of integrity as human beings. Honneth (1996) elaborates this convincingly when he connects forms of recognition to orientations to self. My elaboration of Honneth's conception is to try and get a glimpse of how existing criteria for recognition are challenged and new ones are elicited by means of ordinary, often habitual practices. I am specifically concerned with what I term 'adult recognition,' with how norms about full personhood ${ }^{[3]}$ arise from everyday practices.

\section{Classic markers of adulthood, criteria for adult recognition}

9.1 In order to approach adulthood through this theoretical lens, Eisenstadt's claim-a claim that needs to be read in the social-theoretical context of the times-is a good starting point: '[there is] one focal point within the life span of an individual which is to some extent emphasized in most known societies, namely the achievement of full adult status, or full membership in the social system' (1971: 30). In western societies such status is symbolized through 'the ideas of autonomy, self-determination and choice' (Hockey \& James 1993: 3). These constitutive aspects of what it means to be an adult, a full person and social member, are excluded from our conceptions of childhood, adolescence and old age. Indeed, so powerful is the association of full personhood with adulthood that biologically mature individuals who do not embody competence aspects of the ideal model, such as individuals with disabilities, the frail, the mentally ill, non-residents, the incarcerated, etc., are relegated to the marginal position of a quasi-childhood (Hockey \& James 1993). Adults are individuals who can be full partners in interaction because they are formally as well as informally acknowledged and validated as such. Across recent history, this is the core and constant meaning of adulthood as a social category. To exemplify the social constitution of (standard) adulthood I draw on the classic markers, connect them to criteria for adult recognition and establish what is no more than a crude, orientating typology:

- (a) Marriage attracts adult recognition because it connotes the achievement of adulthood through the recognition of individuals as committed and responsible.

- (b) Parenthood entails a kind of adult recognition that is reliant upon the existence of at least one other human being (a child) for normative validity. This is adulthood as a function of the social recognition of the shared demands, challenges and joys of parenthood, of one's ability to extend care to others and into the future to another generation. To somewhat liberally appropriate a term coined by Erikson (1950), this is recognition based on generativity.

- (c) Independence attained through work leads to social recognition based on performance, productivity and one's contribution to society in societies where work is a central hub on which the validation of personhood hinges.

- (d) Intimately connected to work, independent living connotes adulthood as a function of the 
recognition of independence gained through the transformation of productive competencies into creative action. This is recognition based on creativity, which is perhaps best expressed by the colloquialism 'having something to show for'.

9.2 Adult recognition through commitment and responsibility, productivity and performance, generativity and creativity, implies that being adult is not something we can simply claim for ourselves. Individuals' adult status ultimately relies on the extent to which the things they do and say, and the attitudes and beliefs they hold and express, match the social norms or criteria and expectations of what constitutes adult behaviour and attitudes in society. Subjective identifications and social validation intertwine. Thus, the more closely our practices and behaviours match the normative expectations of adulthood the more deeply etched in individuals' self-perception and bearing will be their self-understanding as adults. Again, from this perspective the personalization of adulthood can only to a very restricted degree be subject to individual decision-making and perception.

9.3 Today the fundamental problem concerning the meaning of adulthood is that the circumstances under which processes of adult recognition take place are today much more fluid and indeterminate than has been the case at the time when the standard model of adulthood emerged. From negotiated personal relationships in cohabitation, family life and parenting to the vagaries of the labour market, from the caprice of fashion in commodities and entertainment to political concerns of globalization, we face a social world in which flexibility and mobility are desirable personal characteristics. The more the social imperative of flexibility becomes normalized and taken for granted, the more likely it is that criteria for the recognition of adult status will be in accord with this imperative. And that means that individuals who are open to change, and tolerant of both external and internal instability and flux, are likely to be validated for their capacity to make on-demand contributions (e.g. in the labour market).

9.4 The redefinition of contemporary adulthood can thus be situated in the prevalent fluidity and pluralization of the interactions in which recognition is now embedded. This is commensurate with Honneth's attempt to theorize the highly differentiated quality of what he calls the 'capitalist recognition order' (Fraser \& Honneth 2003: 138). There is considerable tension in this situation since adulthood as a social category has for so long meant the exact opposite of a fluid and indeterminate way of being in the world. It still resonates with 'settling down,' acquiring a stable social profile, carving out one's life trajectory in terms of long-term goals, and so forth. Today, individuals' ability to be full persons in interaction is at least partly linked to their competence in negotiating their biographies in the context of normative uncertainty. The implication here is that the normative basis for adulthood is no longer clear, since the established collective markers of the transition to adulthood are losing their significance. Their cultural foothold has been so secure, however, that a new understanding of adulthood has not as yet emerged in a coherent way. We are not yet fully aware or ready to admit that far from delaying their adulthood, the 'new adults' (Wyn 2004) are actually very well integrated into their social world. Their practices and attitudes cohere with extant social conditions; and these are likely to be reproduced as rational responses to systemic uncertainty, to invoke Bauman once more. And so, precisely those social trends that are purported to be indicative of a delayed adulthood are highly congruent with contemporary dynamics of adult recognition.

9.5 Nonetheless, contemporary adulthood evinces contradictions that are testimony to its emergent status: it is subject to a recognition deficit because practices may be at once structurally rewarded and discursively misrecognised. For example, short-term goals, loose personal ties and geographical mobility are rewarded by the labour market where '[t]he ideal image,' to quote Beck and Beck-Gernsheim,' 'is that of a completely mobile individual regarding him/herself as a functioning flexible work unit, competitive and ambitious, prepared to disregard the social commitments linked to his/her existence and identity' (Beck and Beck-Gernsheim 1995: 6). Here a prolonged education offers the main opportunities to further one's life chances. But at the same time precisely those practices that are most amenable to integration in the sphere of work, including adaptive changes in the intimate sphere, are misunderstood as indicators of a rejection of commitment, a repudiation of long-term planning and a refusal of responsibility (e.g. Bauman 2003). There is, then, a normative lag between the structural transformations in the organization of work and intimate relationships, the conditions of recognition that obtain in those spheres, and the public and social scientific judgments that are made about social trends-trends which are in fact highly conducive and amenable to these transformations.

9.6 Under these circumstances it is not surprising that contemporary young adults themselves are often unsure about their status. For however alien notions of long-term employment, family, marriage and independent living are for many of them, in the final analysis it is precisely these objective markers and social badges of adulthood that are most overtly connected with being grown up. But at the same time, these young adults also feel uneasy about some of the attitudinal aspects they attribute to that adulthood; and invariably they see that kind of adulthood as belonging to another generation. As Christopher remarks: 'We are told it's a process with an endpoint that you arrive at, but I can't imagine how I'll ever arrive at that 
endpoint'. There is, then, a distinct sense that these young people live two adulthoods: one that is authentic and 'in here,' and one that is inauthentic and 'out there.' They are defining for themselves modalities of adulthood at once against and within the normative constraints of an inherited standard. That is to say, they assert their own adulthoods against the other in so far as their practices and orientations conflict with that ideal; and they forge their adulthoods within the other in so far as the latter still constitutes a part of the world in which they have to live - albeit a world in the redefinition of which they are most actively engaged.

\section{Notes}

${ }^{1}$ I would like to thank three anonymous reviewers for their insightful remarks.

2 By 'planning' in this context I do not mean a systematic construction of strategies aimed at an instrumental unfolding of the life course, but rather a natural attitude, a taken-for-granted stance toward the future regardless of the actual unpredictability of the future.

3'Personhood' is not intended to signify a reified notion of identity. I simply refer here to the commonsense construction of individuals who are no longer (or not yet) considered and/or treated like children, much in the way this is done by Hockey and James (1993); individuals who, through the interplay of biological and social factors have accomplished the transition from 'human becoming' to 'human being'.

\section{References}

ARNETT, J. J. (1997) Young People's Conceptions of the Transition to Adulthood', Youth and Society, Vol. 29, No. 1, pp. 3-21.

ARNETT, J. J. (2000a) 'Emerging Adulthood: A Theory of Development from the Teens through the Twenties', Vol. 55, No. 5, pp. 469-80.

ARNETT, J. J. (2000b) 'High Hopes in a Grim World: Emerging Adults' View of Their Futures and "Generation X", Vol. 31, No. 3, pp. 267-86.

ARNETT, J. J. (2004) Emerging Adulthood: The Winding Road from the Late Teens through the Twenties . New York: Oxford University Press.

ARNETT, J. J. and Taber, S. (1994) 'Adolescence Terminable and Interminable: When Does It End?', Journal Of Youth And Adolescence, Vol. 23, pp. 517-39.

BAUMAN, Z. (2001) The Individualized Society. Cambridge: Polity.

BAUMAN, Z. (2003) Liquid Love: On the Frailty of Human Bonds . Cambridge: Polity.

BECK, U. (1992) Risk Society: Towards a New Modernity. London: Sage.

BECK, U. and BECK-GERNSHEIM, E. (1995) The Normal Chaos of Love . Cambridge: Polity.

BECK, U., GIDDENS, A. and LASH, S. (1994) Reflexive Modernisation: Politics, Tradition and Aesthetics in the Modern Social Order. Cambridge: Polity.

BLATTERER, H. (2007) Coming of Age in Times of Uncertainty, New York and Oxford: Berghahn Books.

BLOS, P. (1941) The Adolescent Personality: A Study of Individuals Behavior for the Commission on Secondary School Curriculum of the Progressive Education Association. New York: Appleton.

CÔTÉ, J. E. (2000) Arrested Adulthood: The Changing Nature of Maturity and Identity . New York: New York University Press.

CRAWFORD, K. (2006) Adult Themes. Sydney: Pan Macmillan.

CROUCH, M. and MCKENZIE, H. (2006) 'The Logic of Small Samples in Qualitative Research', Social Science Information, Social Science Information, vol. 45, 483-499. Vol. 45, pp. 483-499.

DILTHEY, W. (1986) The Hermeneutics Reader: Texts in the German Tradition from the Enlightenment to the Present, Oxford: Blackwell.

DWYER, P. and WYN, J. (2001) Youth, Education and Risk: Facing the Future. London: Routledge. 
EISENSTADT, S. (1971) From Generation to Generation: Age Groups and Social Structure. New York: Free Press.

ELIAS, N. (1978) The Civilizing Process: The History of Manners. Vol 1. Oxford: Blackwell.

ERIKSON, E. (1950) Childhood and Society. New York: Norton.

ERIKSON, E. (1968) Identity: Youth and Crisis. New York: Norton.

FORD, C., ENGLISH, A. and SIGMAN, G. (2004) 'Confidential Health Care for Adolescents: Position Paper of the Society for Adolescent Medicine', Journal of Adolescent Health 35, No. 2, pp. 160-67.

FUREDI, F. (2003) 'Children Who Won’t Grow Up', Spiked Online, .

FURSTENBERG, F. F. (2000) 'The Sociology of Adolescence and Youth in the 1990s: A Critical Commentary', Journal of Marriage and the Family , No. 62, pp. 896-910.

FURSTENBERG, Frank F., KENNEDY, S. MCCLOYD, V. C., RUMBAUT, R. G. and SETTERSTEN, R. A. (2003) 'Between Adolescence and Adulthood: Expectations about the Timing of Adulthood', The Network of Transitions to Adulthood. Philadelphia: The MacArthur Foundation.

GIDDENS, A. (1990) The Consequences of Modernity . Cambridge: Polity.

GIDDENS, A. (1991) Modernity and Self-Identity: Self and Society in the Late Modern Age. Oxford and Cambridge: Polity.

GIDDENS, A. (1992) The Transformation of Intimacy: Sexuality, Love and Eroticism in Modern Societies . Oxford and Cambridge: Polity.

GOFFMAN, E. (1986) Stigma: Notes on the Management of Spoiled Identity . New York: Simon and Schuster.

HALBWACHS, M. (1992) On Collective Memory. Chicago: Chicago University Press.

HALL, S. G. (1904) Adolescence: Its Psychology and its Relations to Anthropology, Sociology, Sex, Crime, Religion and Education. New York: Appleton.

HAMILTON, C. and DENNIS, R. (2005) Affluenza: When Too Much is Never Enough. Sydney: Allen and Unwin.

HERALD SUN (2003) 'Kids Who Refuse to Grow Up’, December 4.

HERALD SUN (2004) '“Adults” Fail the Age Test', August 3.

HOBSBAWM, E. (1996) The Age of Extremes: The Short Twentieth Century 1914-1991. London: Abacus. HOCKEY, J. and JAMES, A. (1993) Growing Up and Growing Old: Ageing and Dependency in the Life Course. London: Sage.

HOCKEY, J. and JAMES, A. (2003) Social Identities Across the Life Course. Basingstoke: Palgrave Macmillan.

HOLDSWORTH, C. and MORGAN, D. (2005) Transitions in Context: Leaving Home, Independence and Adulthood. New York: Open University Press.

HONNETH, A. (1995) The Fragmented World of the Social: Essays in Social and Political Philosophy . New York: State University of New York Press.

HONNETH, A. (1996) The Struggle for Recognition: The Moral Grammar of Social Conflicts . Cambridge: MIT Press.

HONNETH, A. (2003) 'Redistribution as Recognition: A Response to Nancy Fraser', In Redistribution or Recognition? London: Verso.

JAMIESON, L. (1998) Intimacy: Personal Relationships in Modern Societies. Cambridge: Polity.

KOHLI, M. (1986) 'The World We Forgot: A Historical Review of the Life Course', In V. W. Marshall (editor) Later Life: The Social Psychology of Aging . Beverly Hills: Sage. 
LEE, N. (2001) Childhood and Society: Growing Up in an Age of Uncertainty. Buckingham: Open University Press.

MIROWSKY, J. and ROSS, C. (2003) Social Causes of Psychological Distress . New York: de Gruyter. MXAUSTRALIA (2004) 'Forever Young Adultescents Won't Grow Up', February 4.

PARSONS, T. (1954) 'The Kinship System of the Contemporary United States', In Essays in Sociological Theory. New York: Free Press.

PILCHER, J. (1995) Age and Generation in Modern Britain. New York: Oxford University Press.

PILCHER, J., WILLIAMS, J. and POLE, C. (2003) 'Rethinking Adulthood: Families, Transitions, and Social Change', Sociological Research Online, Vol. 8, No. 4, .

QVORTRUP, J. (1994) 'Childhood Matters: An Introduction', In J. Qvortrup, M. Bardy, G. Sgritta, and H. Wintersberger (editors) Childhood Matters: Social Theory, Practice and Politics . Aldershot: Avebury.

SETTERSTEN, R. A. (2003) 'Age Structuring and the Rhythm of the Life Course', In J. T. Mortimer and M. Shanahan (editors) Handbook Of The Life Course. New York: Plenum.

THE AUSTRALIAN (2001) 'Now Wait Til 35 for Coming of Age', September 3.

THORNTON, A. and YOUNG DE MARCO, L. (2001) 'Four Decades of Trends in Attitudes Toward Family Issues in the United States', Journal of Marriage and the Family, Vol. 63, No. 4, pp. 1009-37.

TIME (2005) 'Grow Up? Not So Fast', January 25.

WYN, J. (2004) Becoming Adult in the 2000s: New transitions and New Careers', Family Matters, No. 68, pp. 6-12.

WYN, J. and WHITE, R. (2000) 'Negotiating Social Change: The Paradox of Youth', Youth and Society, Vol. 32, No. 2, pp. 65-83.

ZELDIN, T. (1994) An Intimate History of Humanity. New York: Harper Collins. 